\title{
APRENDIZAGEM E COMPETÊNCIA: UMA ANÁLISE DA BASE NACIONAL COMUM CURRICULAR (BNCC)
}

\author{
LEARNING AND SKILLS: AN ANALYSIS OF BASE \\ NACIONAL COMUM CURRICULAR (BNCC) \\ APRENDIZAJE Y COMPETENCIAS: ANÁLISIS DE \\ LA BASE NACIONAL COMUM CURRICULAR (BNCC)
}

Deise ANDreia ENZWEILER ${ }^{\mathrm{I}}$

I Universidade do Vale do Rio dos Sinos (UNISINOS), São Leopoldo. Rio Grande do Sul/RS-Brasil

Subvenção CAPES

\begin{abstract}
RESUMO O objetivo deste artigo é problematizar a concepção de aprendizagem a partir de três documentos oficiais recentes da educação brasileira: as Diretrizes Curriculares Nacionais Gerais para a Educação Básica (2010); o Plano Nacional de Educação (2014) e a Base Nacional Comum Curricular - BNCC (2018). As reflexões aqui propostas se ancoram metodologicamente ao campo dos Estudos Foucaultianos e analiticamente em autores da teorização social contemporânea e dos Estudos Curriculares. Como conclusão desta análise, que configura um recorte de pesquisas ainda em andamento, destaca-se que há ênfases distintas em relação à aprendizagem, especialmente com as novas proposições apresentadas na BNCC.
\end{abstract}

Palavras-chave: Aprendizagem; Competências; BNCC; Currículo.

ABSTRACT This article aims to problematize learning conception analyzing three official and recent documents from Brazilian education: Diretrizes Curriculares Nacionais Gerais para Educação Básica (2010); Plano Nacional de Educação (2014) e Base Nacional Comum Curricular - BNCC (2018). These reviews are methodological connected to the Foucauldian studies in education. For theoretical analysis, different researchers and authors from social and contemporary theorization were used. As a conclusion, considering this study as part of a research still in progress, it is possible to affirm that actually, there are 
different emphases about learning in the analyzed documents, especially with the recent propositions presented in BNCC.

Keywords: LeAning; Skills; BNCC; Curriculum.

RESUMEN El objetivo de este artículo es problematizar la concepción de aprendizaje a partir del análisis de tres documentos oficiales recientes de la educación brasileña: Diretrizes Curriculares Nacionais Gerais para a Educação Básica (2010); Plano Nacional de Educação (2014) y Base Nacional Comum Curricular - BNCC (2018). Las reflexiones propuestas se anclan metodológicamente al campo de los Estudios Foucaultianos y analíticamente en autores de la teorización social contemporánea y de los Estudios Curriculares. Como conclusión de este análisis, que configura un recorte de investigaciones que siguen en desarrollo, se destaca que hay énfasis distintos en relación al aprendizaje, especialmente con las nuevas proposiciones pedagógicas presentadas en la BNCC.

Palabras Clave: Aprendizaje; Competencias; BNCC; Plan de estúdios.

\section{INTRODUÇÃo}

Agir pessoal e coletivamente com autonomia, responsabilidade, flexibilidade, resiliência e determinação, tomando decisões com base em princípios éticos, democráticos, inclusivos, sustentáveis e solidários (BRASIL, 2018).

O pequeno trecho citado compõe uma entre as dez competências gerais sugeridas pela Base Nacional Comum Curricular (BNCC). A décima competência, já destacada, expõe, em suas proposições, algumas das ênfases em relação à aprendizagem que este texto objetiva problematizar. Segundo Silva (2017, p. 31), ao analisar o período recente e os embates relacionados à regulação e seleção do conhecimento, "noções como expectativas de aprendizagem, currículo mínimo, direitos de aprendizagem, competências cognitivas e socioemocionais, dentre outras, foram utilizadas no decorrer deste processo de longos embates políticos". Nesse sentido, se enfatiza que o conceito pedagógico central da Base é o de competência. As noções ressaltadas por Silva (2017) sinalizam variados elementos presentes na elaboração conceitual desse documento. Apesar de iniciar com essas pontuações diretas sobre a BNCC, interessa, nesta análise específica, problematizar concepções de aprendizagem a partir de três documentos oficiais recentes da educação brasileira, sustentando-se que a BNCC, entre eles, sintetiza um novo momento pedagógico nas proposições curriculares nacionais ao centralizar o conceito de competências para pensar as práticas pedagógicas e os processos de aprendizagem. Partindo-se de um ponto de vista educacional, tal como sugerem Masschelein e Simons (2017), a análise de tais documentos não visa um esgotamento analítico, mas a compreensão de distintos momentos e embasamentos para a formulação de políticas educacionais.

A problematização que se propõe parte da premissa que a BNCC, ao pontuar uma conexão intrínseca entre aprendizagem e competência, estaria indicando novas ancoragens conceituais para a aprendizagem. Ao materializar, no contexto brasileiro, proposições que têm pautado a educação no espectro mundial, a partir de orientações de grandes órgãos internacionais e, da mesma forma, pelas proposições teóricas que subsidiam as questões 
de ordem pedagógica, é possível afirmar que a BNCC reitera questões que já se enfatizavam em documentos anteriores, como aqueles que serão aqui analisados. Entretanto, há considerações importantes que podem ser compreendidas como novidades em relação às proposições curriculares e conceituais anteriores. Inicialmente, destaca-se que as Diretrizes Curriculares Nacionais Gerais para a Educação Básica (DCN) e o Plano Nacional de Educação (PNE), apesar de também indicarem em suas proposições determinadas indicações teóricas a respeito da aprendizagem, como será abordado mais adiante, apontam um foco constante nas questões das desigualdades do contexto brasileiro, especialmente pela ideia de educação pela qualidade pedagógica e social.

Assim, a partir do objetivo do presente artigo, propõe-se realizar uma análise desses três documentos recentes no campo das políticas educacionais brasileiras a fim de problematizar as concepções de aprendizagem aí implicadas. Tais documentos, que abrangem o período que varia de 2010 a 2018, não são documentos da mesma natureza, como se explica mais adiante. Metodologicamente, parte-se do campo dos estudos foucaultianos, utilizando-se da ferramenta do discurso (FOUCAULT, 2008) para proceder à análise dos documentos eleitos para tal. Justifica-se essa escolha pela possibilidade de minimamente mapear os campos discursivos que têm subsidiado as proposições em curso, bem como, para identificar o que tem se sobressaído nas enunciações produzidas no campo educacional.

Para a organização dessa análise, o artigo foi organizado em três seções distintas. Na primeira seção, intitulada Aprendizagem no cenário contemporâneo, tem-se como objetivo justificar o porquê do interesse em olhar criticamente para as compreensões de aprendizagem nos documentos eleitos para esse exercício, caracterizando-se a sua relevância no cenário educacional contemporâneo a partir de variados autores do campo pedagógico e educacional. Já na segunda seção, intitulada Uma breve incursão nos documentos, o foco principal está em fazer uma apresentação sucinta dos documentos, destacando elementos relativos à aprendizagem e seus entendimentos pedagógicos nos respectivos documentos. Nessa mesma seção, são pontuadas as definições teórico-metodológicas da análise realizada. E na terceira e última seção, intitulada Aprendizagem e competência: a BNCC em foco, são elaborados basicamente dois exercícios reflexivos a partir dos documentos, tecendo algumas interlocuções com teóricos contemporâneos que têm tensionado e problematizado o campo educacional e social, de maneira ampla, bem como, outros que têm esboçado críticas mais específicas ao campo pedagógico, especialmente pela forma como algumas mudanças têm impactado as questões curriculares, o ensino e a aprendizagem.

\section{APRENDIZAGEM NO CENÁRIO CONTEMPORÂNEO}

\footnotetext{
A sociedade contemporânea impõe um olhar inovador e inclusivo a questões centrais do processo educativo: o que aprender, para que aprender, como ensinar, como promover redes de aprendizagem colaborativa e como avaliar o aprendizado (BRASIL, 2018).
}

Pensar a aprendizagem no cenário atual implica um olhar que extrapole o campo educacional e pedagógico. Nessa perspectiva, Noguera-Ramirez (2011), Biesta (2013a, 2013b) 
e outros, desde esses campos, têm sinalizado um deslocamento de uma ênfase na aprendizagem em detrimento do ensino. Esse deslocamento pode ser atribuído e analisado por fatores de ordens variadas. Uma dessas implicações, apontada por Laval (2004), sugere que a demanda por inovações, tal qual também sugere a BNCC, por exemplo, mesmo que com objetivos essencialmente de ordem econômica, têm se traduzido em diferentes textos de referência por definições muito amplas que remetem à plenitude pessoal, à cidadania ativa e também à integração social. Para o referido autor, "esse novo paradigma quer responsabilizar os cidadãos por seu dever de aprender" (LAVAL, 2004, p. 51).

Nesse quadro analítico, inclusive as questões do ensino escolar, quando tematizadas, já não se atrelam a um tipo de escola instrucional e/ou disciplinar, mas também são comumente compreendidas pelo viés da aprendizagem. Nesse sentido, "numerosos docentes desejam abandonar a tradição que consiste principalmente em transmitir conhecimento a seus alunos e preferem fazê-los aprender a refletir e a aprender por si mesmos" (LAVAL, 2004, p. 59). Entretanto, esses deslocamentos perceptíveis no campo educacional e pedagógico não são uma exclusividade do respectivo campo em discussão. De acordo com Narodowski (2016), muitas mudanças que têm se sucedido nas sociedades contemporâneas não são fatos isolados, como a "crise da escola", por exemplo, mas se atrelam a câmbios mais amplos e complexos das próprias relações sociais. Segundo o autor:

\footnotetext{
Os problemas de legitimidade e atuação que hoje afrontam a instituição escolar moderna (a famosa "crise da escola") têm a ver com câmbios nas relações sociais vinculadas com a forma da transmissão geracional pré-figurativa, com o regime epistêmico que tende a multiplicar e tornar caóticas as suas mudanças e com as mutações na ordem produtiva e familiar (NARODOWSKI, 2016, p. 166). ${ }^{1}$
}

Nesse cenário, a aprendizagem também pode ser compreendida não como um fato que se engrandece exclusivamente por opções de ordem pessoal dos professores ou por uma simples imposição de políticas educacionais mais amplas. Tais deslocamentos e reorganizações conceituais, como esses autores sinalizam, estão atrelados às condições discursivas do tempo presente. Por sua vez, somadas às questões de ordem cultural e social, a partir do que Narodowski (2016) nomeia como uma hipotética sociedade sem adultos, Laval (2016, p. 3) também aponta que desde a perspectiva macroeconômica, "o novo modelo escolar e educativo que tende a se impor está fundamentado, inicialmente, na sujeição mais direta da escola à razão econômica". Portanto, propõe-se que a análise dos documentos que em seguida serão descritos sejam compreendidos dentro de uma atmosfera mais ampla de conjunções variadas.

Ao tomar a temática da aprendizagem como central na discussão que se propõe, faz-se necessário distinguir a crítica à aprendizagem e à linguagem da aprendizagem. Seguindo os estudos de Biesta (2018), a crítica educacional não se remete imediatamente à aprendizagem em si, mas à linguagem da aprendizagem. Para o autor, "a linguagem da aprendizagem é demasiadamente limitada como uma linguagem educacional” (BIESTA, 2018, p. 23), caracterizando-a como vazia de conteúdo e propósito. Segundo as definições educacionais

Tradução da autora. 
do referido autor, a educação deve, sempre, engajar-se em questões de conteúdo, propósito e relações (BIESTA, 2018). Portanto, uma primeira definição importante nas delimitações iniciais é que a crítica não está direcionada à aprendizagem e aos aspectos de consideração individual dos alunos no contexto educacional, mas à forma como essa discursividade torna-se hegemônica, tomando o espaço da dimensão propriamente educacional.

Para Biesta (2018), uma precaução metodológica importante nas análises educacionais é a articulação e o equilíbrio do que denomina de três domínios: qualificação, socialização e subjetivação. Segundo o autor, "a educação sempre precisa estar engajada com questões de conteúdo, tradição e liberdade do estudante como sujeito" (BIESTA, 2018, p. 24). Para o autor, uma boa educação, afastada das demandas exclusivas de uma linguagem da aprendizagem, "deve saber que qualificação não é a única coisa que importa, mas que socialização e subjetivação estão também sempre presentes e precisam ser consideradas" (BIESTA, 2018, p. 28). Essas considerações possibilitam pensar a aprendizagem para além de uma questão meramente individualista, apesar de não esquecer e ignorar os aspectos de ordem individual. Para o autor, essa crítica direciona-se mais à possibilidade de estar no mundo (na escola, na sociedade, na família) de "um modo não ego-lógico" (BIESTA, 2018). Portanto, considerando-se a linguagem da aprendizagem (BIESTA, 2013b) como um fenômeno não isolado de outros aspectos do contexto presente, também é possível estabelecer críticas distintas à sua emergência desde os autores por ora exibidos.

$\mathrm{Na}$ mesma perspectiva da crítica estabelecida, Biesta (2013b) pela linguagem da aprendizagem, Simons e Masschelein (2017), sinalizam que hoje, ao se falar de educação escolar tende-se, invariavelmente, a falar sobre aprendizagem. Como um conceito amplo, pode atrelar-se a distintos campos de saber: psicológico, econômico, sociológico, biológico, neurocientífico e até educacional (SIMONS; MASSCHELEIN, 2017). Independentemente do campo ao qual se conecta, a sua definição pouco se altera, estando sempre ligada à ideia de processo, como uma forma de mutação individual. De acordo com Simons e Masschelein (2017, p. 41), a aprendizagem pode ser assim definida:

Fala-se dela como um processo, e assim é abordada, como se tivesse um começo
e um fim. O fim é comumente tratado em termos de conhecimento, habilida-
des, atitudes e competências. O processo propriamente dito é visto como uma
força de transformação, ou cada vez mais como um processo de construção ou
de produção. Aprender é considerado, assim, como um processo de mudança, e
dependendo da abordagem o processo de mudança é conceituado diferentemente.

Assim, ao analisar normativas, princípios e definições curriculares no campo educacional atual, necessita-se de atenção sobre as novas configurações acerca do ensino e da aprendizagem. De acordo com Goodson (2008, p. 15), "as questões relacionadas com o ensino e a educação são claramente influenciadas pelas mudanças colossais que estão ocorrendo atualmente na economia global". Portanto, as análises relativas às proposições curriculares e às concepções de ensino e aprendizagem aí subjacentes devem considerar esses aspectos contextuais, que impactam diretamente a formulação das políticas e diretrizes educacionais. Na mesma perspectiva, Rovai (2010) também destaca o caráter polissêmico do conceito de competência. Segundo seus estudos, o termo competências (no plural) "vem 
sendo empregado para designar os conteúdos específicos de cada qualificação ocupacional" (ROVAI, 2010, p. 17). No entanto, o termo competência (no singular), "designa um conjunto de qualidades a ser desenvolvido pela pessoa em seu processo de formação profissional, fruto de interações entre uma estrutura bem organizada de conhecimentos e a experiência prática" (ROVAI, 2010, p. 18). Portanto, inúmeras são as possiblidades de compreensão da BNCC e das competências por ela estipuladas. Na sequência, adentra-se na breve descrição de alguns documentos que compõem as bases e os dados a partir dos quais se objetiva reformulações curriculares condizentes com as características da sociedade contemporânea e as novas necessidades econômicas globais.

\section{UMA BREVE INCURSÃO NOS DOCUMENTOS}

Para a realização desta análise, utilizou-se um tipo de inspiração metodológica a partir do campo dos Estudos Foucaultianos visando à problematização da concepção de aprendizagem a partir de três documentos oficiais recentes da educação brasileira. Conforme Foucault (2008), o discurso constitui os objetos aos quais se refere. Portanto, a ferramenta conceitual para essa construção delimitou-se como o discurso. Neste caso analítico, podemos afirmar que os discursos constituem compreensões acerca do conceito aprendizagem profundamente articulados às possibilidades de enunciação de determinada época. Conforme será destacado na terceira e última seção, de cunho analítico, as evidências possíveis de serem observadas nas normativas aqui implicadas estão enredadas em processos de transformação e deslocamentos visíveis também em outras superfícies. Portanto, pode-se compreender que tais mutações não são fatos isolados ou que se sucedem de forma "natural", mas que são efeitos de conjunturas amplas e complexas, que abarcam desde o cenário econômico e político ao campo social e cultural.

De acordo com Veiga-Neto (2011, p. 100), "os discursos não estão ancorados ultimamente em nenhum lugar, mas se distribuem difusamente pelo tecido social, de modo a marcar o pensamento de cada época, em cada lugar, e, a partir daí, construir subjetividades". Dessa forma, elege-se a ferramenta do discurso para analisar os documentos a serem posteriormente apresentados com o objetivo de problematizar a concepção de aprendizagem a partir de três documentos oficiais recentes da educação brasileira. Como se evidencia na primeira seção, especialmente a partir das pesquisas de Biesta (2013a; 2013b), falar sobre a aprendizagem se tornou algo tão naturalizado que muitos campos, para além do educacional, o fazem. Por sua vez, a sua naturalização também leva quase a sobrepô-la ao sentido de educação, invariavelmente confundindo-se. Portanto, a partir dos autores que subsidiam a crítica a determinadas apreensões da aprendizagem no campo educacional, propõe-se uma análise discursiva dos documentos, no intuito de evidenciar como diferentes "discursos definem regimes de verdade" (VEIGA-NETO, 2011, p. 101).

Partindo de um cenário em que, na possibilidade de leitura de um contexto mais ampliado, observa-se a prevalência de uma discursividade específica sobre aprendizagem no contexto brasileiro que pode ser destacado, por exemplo, na atmosfera de documentos educacionais, é que essa discussão se desencadeia. Buscando compreender algumas nuances a 
respeito de tais engendramentos em normativas recentes do Brasil, optou-se pela análise de três documentos distintos que delimitam desde questões curriculares até metas educacionais para o país. Nesse sentido, faz-se uma ressalva antes de prosseguir à breve descrição de tais documentos: as DCN e BNCC têm objetivos específicos distintos do PNE.

Assim, enquanto os dois primeiros documentos têm objetivos de ordem curricular, o PNE está direcionado ao planejamento e à estipulação de metas educacionais. Entretanto, por abarcar questões de ordem estratégica, como forma de dar conta das 20 metas estipuladas para a educação brasileira no período de 2014 a 2024, tempo de sua vigência, compreende-se que as questões relativas à aprendizagem também são destaques na formulação de tal documento. Portanto, apesar de não se configurarem como documentos de ordem semelhante, a comparação que se objetiva com as suas respectivas análises é relativa às concepções de aprendizagem e suas respectivas ênfases. Assim, suas especificidades, apesar de distintas, podem ser compreendidas como resultados de um mesmo momento histórico e, por isso, são analisadas conjuntamente nesse momento: 1) Diretrizes Curriculares Nacionais Gerais para a Educação Básica (BRASIL, 2013); 2) Plano Nacional de Educação (BRASIL, 2014); e 3) Base Nacional Comum Curricular (BRASIL, 2018).

As Diretrizes, divulgadas em 2010, têm como foco formativo, conforme excerto no quadro a seguir, a ideia de uma educação com qualidade social. De modo diferente da $\mathrm{BNCC}$, as DCN não são normativas, mas orientações visando às reformulações curriculares. De acordo com suas formulações, a qualidade social tem duas dimensões: qualidade pedagógica e qualidade política. Em sua redação, evidencia-se uma preocupação com desigualdades variadas, desde questões de ordem social até questões voltadas a grupos específicos, como indígenas, afrodescendentes e deficientes. A aprendizagem, por sua vez, aparece pontuada pela necessidade de qualificar e alavancar índices educacionais, bem como, uma preocupação acentuada com a necessidade de compreensão histórica da constituição do Brasil e com foco curricular no conhecimento, específico e geral.

Quadro 1: Diretrizes Curriculares Nacionais Gerais para a Educação Básica.

O conceito de qualidade na escola, numa perspectiva ampla e basilar, remete a uma determinada ideia de qualidade de vida na sociedade e no planeta Terra. Inclui tanto a qualidade pedagógica quanto a qualidade política, uma vez que requer compromisso com a permanência do estudante na escola, com sucesso e valorização dos profissionais da educação. Trata-se da exigência de se conceber a qualidade na escola como qualidade social, que se conquista por meio de acordo coletivo. Ambas as qualidades - pedagógica e política - abrangem diversos modos avaliativos comprometidos com a aprendizagem do estudante, interpretados como indicações que se interpenetram ao longo do processo didático-pedagógico, o qual tem como alvo o desenvolvimento do conhecimento e dos saberes construídos histórica e socialmente.

Fonte: BRASIL (2013, p. 22).

O PNE, por sua vez, explora o mesmo conceito de qualidade social destacado pelas Diretrizes, divulgadas no ano de 2010. As diretrizes que inicialmente o sustentam, evidenciam preocupações de ordens distintas. Por um lado, percebe-se um foco acentuado na superação de desigualdades básicas, como erradicação do analfabetismo e com a universalização do atendimento escolar. Por outro lado, se destaca uma preocupação com o conhecimento esco- 
lar, com a melhoria da qualidade escolar, com a formação para a cidadania e com a constituição de uma educação ampla, voltada à superação de desigualdades sociais históricas. As questões da cidadania aparecem de forma relevante, pontuadas por foco nos direitos e na educação socioambiental, por exemplo, como pode se averiguado no quadro a seguir:

\section{Quadro 2: Plano Nacional de Educação.}

Artigo 2o São diretrizes do PNE:

I - Erradicação do analfabetismo;

II - Universalização do atendimento escolar;

III - superação das desigualdades educacionais, com ênfase na promoção da cidadania e na erradicação de todas as formas de discriminação;

IV - Melhoria da qualidade da educação;

V - Formação para o trabalho e para a cidadania, com ênfase nos valores morais e éticos em que se fundamenta a sociedade;

VI - Promoção do princípio da gestão democrática da educação pública;

VII - promoção humanística, científica, cultural e tecnológica do País;

VIII - estabelecimento de meta de aplicação de recursos públicos em educação como proporção do Produto Interno Bruto - PIB, que assegure atendimento às necessidades de expansão, com padrão de qualidade e equidade;

IX - Valorização dos(as) profissionais da educação;

$\mathrm{X}$ - Promoção dos princípios do respeito aos direitos humanos, à diversidade e à sustentabilidade socioambiental.

Fonte: BRASIL (2014).

Apesar dessas percepções gerais acerca do PNE, também é possível averiguar que pelo estabelecimento das 20 metas e de suas respectivas estratégias, há concomitantemente às diretrizes já destacadas, uma presença marcante das metas educacionais, pautadas pela necessidade de alavancar índices. Assim, apesar de se enfatizar que conceitualmente o PNE se mostra focado na superação de desigualdades históricas e na superação de elementos básicos no campo educacional, como a universalização da Educação Básica, por exemplo, suas metas se mostram focadas em índices educacionais que, por um lado, homogeneízam realidades até então descritas como profundamente desiguais, como aponta a meta $\mathrm{n}^{\circ} .7$. Por outro lado, como apontam as metas $\mathrm{n}^{\circ} .8$ e $\mathrm{n}^{\circ} .9$, as próprias desigualdades indicadas pelo PNE são alvo de idealizações estatísticas para a sua superação, como a educação de jovens e adultos que não concluíram os estudos na idade "adequada", bem como os índices de alfabetização desse público específico.

A BNCC, por sua vez, não destaca de forma central questões relativas às desigualdades ou a uma educação de qualidade social, como os dois documentos anteriores. A palavra competência, central na BNCC, não é uma novidade nas formulações educacionais recentes. Por exemplo, nas DCN, a palavra competência já aparece articulada a palavras como habilidades e atitudes. Entretanto, ela se destaca nas questões relativas à Educação Profissional Técnica ao explorar especificidades na formação do trabalhador. Nos demais usos das Diretrizes, a competência ocorre de uma forma ampla e em usos variados: por exemplo, 
nas referências aos direitos humanos como eixo norteador das organizações curriculares. No entanto, seu uso não acontece de modo tão recorrente nas questões especificamente pedagógicas. Já na BNCC, é possível defini-la como o conceito pedagógico central. Também se utiliza a ideia de competência como um "guarda-chuva" que abarca definições variadas e relacionadas, como aprendizagem, habilidades, atitudes e valores.

\section{Quadro 3: Algumas Metas do PNE.}

Meta 7: Fomentar a qualidade da educação básica em todas as etapas e modalidades, com melhoria do fluxo escolar e da aprendizagem, de modo a atingir as seguintes médias nacionais para o IDEB: 6,0 nos anos iniciais do ensino fundamental; 5,5 nos anos finais do ensino fundamental; 5,2 no ensino médio.

Meta 8: Elevar a escolaridade média da população de 18 (dezoito) a 29 (vinte e nove) anos, de modo a alcançar, no mínimo, 12 (doze) anos de estudo no último ano de vigência deste Plano, para as populações do campo, da região de menor escolaridade no País e dos $25 \%$ (vinte e cinco por cento) mais pobres, e igualar a escolaridade média entre negros e não negros declarados à Fundação Instituto Brasileiro de Geografia e Estatística - IBGE.

Meta 9: Elevar a taxa de alfabetização da população com 15 (quinze) anos ou mais para 93,5\% (noventa e três inteiros e cinco décimos por cento) até 2015 e, até o final da vigência deste PNE, erradicar o analfabetismo absoluto e reduzir em 50\% (cinquenta por cento) a taxa de analfabetismo funcional.

Fonte: BRASIL, 2014.

Quadro 4: Base Nacional Comum Curricular.

Na BNCC, competência é definida como a mobilização de conhecimentos (conceitos e procedimentos), habilidades (práticas, cognitivas e socioemocionais), atitudes e valores para resolver demandas complexas da vida cotidiana, do pleno exercício da cidadania e do mundo do trabalho.

Fonte: BRASIL (2018).

De acordo com as definições sugeridas pela BNCC, o foco no desenvolvimento de competências desloca a própria centralidade do conhecimento, como sugeriam os documentos anteriores. O foco no aprender a aprender pressupõe, de um lado, uma formação de tipo mais genérica e ampla, como aponta o excerto destacado a seguir. De outro lado, se enfatizam as questões relativas a um novo tipo de comportamento desejado: mais do que dominar conhecimentos, a BNCC ressalta a proatividade, a autonomia, a necessidade de saber tomar decisões e saber agir em determinadas situações. Portanto, se requer mais do que acúmulo, mas se objetiva a formação de outro tipo de sujeito, marcado por características próprias de um novo tempo. 
No novo cenário mundial, reconhecer-se em seu contexto histórico e cultural, comunicar-se, ser criativo, analítico-crítico, participativo, aberto ao novo, colaborativo, resiliente, produtivo e responsável requer muito mais do que o acúmulo de informações. Requer o desenvolvimento de competências para aprender a aprender, saber lidar com a informação cada vez mais disponível, atuar com discernimento e responsabilidade nos contextos das culturas digitais, aplicar conhecimentos para resolver problemas, ter autonomia para tomar decisões, ser proativo para identificar os dados de uma situação e buscar soluções, conviver e aprender com as diferenças e as diversidades.

Fonte: BRASIL (2018).

Assim, ao apresentar brevemente algumas inclinações de cada um dos documentos eleitos para a análise, percebe-se que a BNCC exibe novidades em relação às orientações anteriores, porém semelhantes em algumas de suas proposições. Conforme as análises que seguem na próxima seção, é possível visualizar que a Base está fortemente articulada a tendências sociais de sua época, bem como às formulações de ordem mundial, especialmente pelo viés econômico. Da mesma forma, pelo foco individualista que a aprendizagem toma ao pautar-se no desenvolvimento de competências, há elementos que talvez extrapolem uma análise exclusivamente econômica, mas que, como sugerem as análises que seguem, estejam conectadas com características de outras figuras subjetivas, como o que Lipovetsky e Serroy (2015) definem como Homo aestheticus. Essa figura, entretanto, não ignora as influências e as tendências próprias de uma perspectiva analítica de cunho econômico, como se destaca na sequência.

\section{APRENDIZAgeM E COMPETÊNCIA: A BNCC EM FOCO}

A partir das descrições estabelecidas na seção anterior e pelo cenário descrito inicialmente, consideram-se, por ora, duas possibilidades analíticas que sinalizam novas ênfases sobre a aprendizagem, especialmente a partir da análise da BNCC. A primeira diz respeito ao que Laval (2004) aponta como o deslocamento da ênfase no conhecimento para a ênfase nas competências. Essa análise tornou-se possível pelas variações de como a aprendizagem apresentou-se nos documentos analisados e, em especial, pela forma como conhecimento e competências aparecem na BNCC. Já a segunda possiblidade analítica está direcionada à leitura das proposições educacionais da BNCC na esteira do capitalismo estético (LIPOVESTSKY; SERROY, 2015), principalmente por duas razões: por todas as questões de ordem comportamental e socioemocional que ocorrem nas justificativas de ordem pedagógica da BNCC e pela exacerbação de um individualismo a partir do entendimento da aprendizagem pelo desenvolvimento de competências.

De acordo com Rios (2010, p. 149), é possível "constatar que a noção de competência importada do mundo empresarial tem sido hegemônica nas propostas, principalmente oficiais, que se apresentam no campo da educação". Para a autora, apesar dessa apropriação, "há a possibilidade de se utilizar a noção de maneira distinta, com um significado mais 
abrangente e despido da marca ideológica de que se revestiu no contexto da tendência tecnicista" (RIOS, 2010, p. 149). Na mesma trilha teórica, Rovai (2010) aponta que a formação por competências surge no campo educacional brasileiro, especialmente na educação profissional, em meados dos anos 1980, a exemplo de outros países integrantes da economia globalizada, consolidando-se nas proposições da Lei de Diretrizes e Bases da Educação Nacional, pela Lei Federal n. 9.394/96 (ROVAI, 2010). Segundo os estudos da referida autoria, surge, assim, um novo modelo de profissionalismo com a lógica da competência, como opção de superação do modelo taylorista-fordista.

Segundo Laval (2004, p. 57), "definida como uma característica individual, a categoria de competência participa da estratégia de individualização, perseguida pelas novas políticas de gestão de recursos humanos". Para o autor, a lógica das competências cada vez mais aproxima os objetivos da empresa e da escola. Aquilo que outrora distanciava consideravelmente os objetivos específicos desses dois espaços, hoje parece cada vez mais aproximá-los, tal como apontam as caracterizações pedagógicas da BNCC. Apesar de identificar que, historicamente, a ideia de competência se conectou a campos distintos e bem diversos entre si, o conceito em voga nas proposições educacionais atuais está atrelado à necessidade a aquisição de competências cognitivas. De acordo com Laval (2004, p. 61):

\footnotetext{
A aprendizagem tem por objeto a aquisição de competências cognitivas, de competências fragmentadas que servem de suporte à determinação pedagógica de objetivos. Esses descrevem, de maneira detalhada, as tarefas a cumprir que mobilizem essas competências às quais, para as necessidades de avaliação, deve poder corresponder, a cada vez, um comportamento observável.
}

A BNCC, ao conectar o conceito de aprendizagem ao desenvolvimento de competências gerais, mostra-se comprometida justamente com as definições elaboradas pelo referido autor. Segundo Laval (2004, p. 61), nessa perspectiva analítica, "os conhecimentos são reinterpretados no léxico das competências, dos objetivos, das avaliações, dos contratos". Entretanto, como se buscou evidenciar nas mutações de um documento para o outro durante o exercício de descrição anterior, as questões da desigualdade, ao serem pontuadas de forma distintas nos documentos em foco, materializam um dos riscos que Laval (2004) abaliza em relação à lógica das competências. De acordo com o autor, ao dar mais prioridade às "qualidades diretamente úteis da personalidade empregável do que a conhecimentos realmente apropriados, mas que não seriam necessariamente e imediatamente úteis economicamente, comporta um sério risco de desintelectualização e desformalização do processo de aprendizagem" (LAVAL, 2004, p. 63). Portanto, ao pautar-se pela liberdade individual, especialmente pela conexão entre aprendizagem e competências, a BNCC evidencia o risco de descaracterizar marcas pedagógicas típicas do espaço escolar, bem como acentuar desigualdades no contexto escolar e social. Como sugere Laval (2004, p. 63), uma das contradições pedagógicas das proposições dessa ordem reside justamente em querer promover aquilo que se está a negar, pois a atividade intelectual não é espontânea, mas é fruto da ação de disciplinas escolares específicas.

A partir de outra linha argumentativa, Lipovestsky e Serroy (2015) apontam algumas questões que, desde esse cenário macro político, econômico e social, evidenciam uma pers- 
pectiva mais individual desse contexto a partir da análise do capitalismo artista. Partindo da construção argumentativa em torno da estetização da vida, os autores pontuam que "o desenvolvimento do capitalismo financeiro contemporâneo não exclui de modo algum a potencialização de um capitalismo de tipo artista em ruptura com o modo de regulação fordiano de economia" (LIPOVESTKY; SERROY, 2015, p. 14). Para os autores, o capitalismo do tipo financeiro não se contrapõe ao capitalismo do tipo artista. Muito ao contrário, ele o alimenta, conduzindo às "dimensões criativas, intuitivas, emocionais" (LIPOVESTKY; SERROY, 2015, p. 15). Como indicam as próprias proposições da BNCC, não basta acumular informações ou ter um diploma, faz-se necessário que os sujeitos sejam resilientes e criativos, como sugerem as reflexões sobre esse viés específico do capitalismo.

Para os autores, os impactos do capitalismo artista podem ser lidos para além do recorte de classe social, pois há "fenômenos presentes em todas as classes sociais ao mesmo tempo em que tendem a se subjetivizar" (LIPOVESTKY; SERROY, 2015, p. 31). Nessa perspectiva, ressaltam a democratização da figura subjetiva que denominam de Homo aestheticus. Segundo Lipovetsky e Serroy $(2015$, p. 31), "o indivíduo transestético é reflexivo, eclético e nômade: menos conformista e mais exigente do que no passado, ele se mostra ao mesmo tempo um drogado do consumo, obcecado pelo descartável, pela celeridade, pelos divertimentos fáceis". Tais características, apesar de não configurarem uma análise desde o campo educacional ou pedagógico, podem facilmente servir de leitura para compreender algumas implicações da BNCC, por exemplo. Ao criticar a escola que ensina conteúdos ou conhecimentos, como algo "pesado" e enfadonho, a BNCC se alinha aos entendimentos acerca de uma perspectiva educacional mais individualizada, em que cada sujeito pode se criar, criar sua trajetória e fazer escolhas exclusivamente de acordo com seus interesses pessoais.

Em outro momento, Lipovetsky (2016) também analisa aquilo que denomina de imperativo da leveza. Segundo o autor, a leveza não está mais associada à falta, mas ao virtual e à mobilidade. Ao tratá-la como um imperativo, o autor também a analisa como um modo de funcionamento econômico, especialmente pela condição de vida "em crise" permanente a qual se está sujeito em um modo de vida neoliberal. Para Lipovetsky (2016, p. 34), é "a própria economia que se encontra reorganizada pelo princípio da leveza, uma vez que o capitalismo de consumo funciona estruturalmente na sedução, na frivolidade, na renovação perpétua dos modelos". Tais condicionamentos também podem ser lidos e compreendidos como marcantes nos direcionamentos propostos pela BNCC. Colocando-se contra o acúmulo (seja de informações, seja de conhecimentos), as proposições em jogo estão mais atreladas a essa condição de leveza: o sujeito precisa demonstrar interesse, proatividade e liberdade no espaço em que está. O imperativo da leveza, marcado pelo viés econômico que também o subsidia, é um modo de consumo que também se percebe pela proposta pedagógica em curso na Base: o interesse, o utilitarismo, a reconfiguração da figura do professor, a necessidade de reinventar aulas dinâmicas, interativas e/ou divertidas. Todas essas colocações sobre a necessidade de inovar e renovar o espaço escolar estão profundamente associadas à necessidade de consumo individual obcecado, sempre marcado pelo interesse e pela vontade de cada um e de suas respectivas necessidades.

De acordo com Silva (2018, p. 553), ao analisar as novas tendências curriculares brasileiras, pode-se afirmar que "contemporaneamente, novas tecnologias pedagógicas são 
colocadas em cena no contexto brasileiro, articulando produtivamente as noções de estetização pedagógica, aprendizagens ativas e práticas curriculares". Para o autor, talvez seja possível vislumbrar a "emergência de um novo arranjo capitalista, no qual as questões de estética, do design e da inovação são potencializadas" (SILVA, 2018, p. 557). Em suas análises, identifica que as novas proposições curriculares, sintonizadas com as condições do neoliberalismo contemporâneo, também estariam condicionando a formação humana para o século XXI a partir de novos engendramentos: a pessoa instruída não se caracterizaria mais pela capacidade de reter conhecimentos, mas pela condição e pela capacidade de aprender permanentemente (SILVA, 2018). A BNCC, portanto, pelas proposições formativas ancoradas na aquisição de competências pela aprendizagem permanente e ininterrupta, seria um exemplo das novas tendências curriculares e educacionais nos novos contextos formativos do século XXI.

A crítica à aprendizagem e à própria aquisição de competências, antes de encerrada, merece uma ressalva. Ao analisar as políticas de inclusão e as práticas pedagógicas inclusivas no cenário brasileiro, Lopes $(2018 \text {, p. } 92)^{2}$ aponta que "fazer críticas a horizontalidade do professor não significa defender a negação das demandas dos alunos e do nosso tempo, tampouco ignorar as realidades econômicas, sociais, religiosas, culturais e as próprias condições individuais de aprendizagem dos alunos". Na mesma perspectiva, a autora assinala a necessidade de atualização de conceitos para a definição de metodologias de ensino e de aprendizagem mais interativas e coerentes com o século XXI. Assim, essa ressalva torna-se fundamental para que a crítica ao que Biesta (2013b) define como a linguagem da aprendizagem não seja tomada como a negação da aprendizagem como uma atividade individual e que, portanto, sempre terá especificidades próprias e individuais. A crítica à aprendizagem e às competências direciona-se a um possível excesso de individualização, no qual as características tipicamente escolares, de ensino, de aprendizagem e de formação, materializadas nas definições curriculares, sejam completamente descaracterizadas, especialmente em contextos educacionais ditos inclusivos. Por fim, parte-se para algumas considerações finais acerca da reflexão aqui sugerida.

\section{CONSIDERAÇÕES FINAIS}

Inicialmente, teve-se como objetivo problematizar a concepção de aprendizagem a partir de três documentos recentes da educação brasileira: as Diretrizes Curriculares Nacionais Gerais para a Educação Básica (2010); o Plano Nacional de Educação (2014) e a Base Nacional Comum Curricular (2018). Após o desenvolvimento das três seções propostas, é possível encerrar estabelecendo algumas considerações de ordem conclusiva. Primeiro, é perceptível, especialmente pelas descrições dos documentos, que a BNCC inaugura algumas questões no campo educacional e pedagógico brasileiro desde o viés das normativas educacionais. Apesar de algumas noções já estarem sinalizadas em documentos anteriores, a Base mostra-se como uma síntese materializada de discussões que variados autores e pesquisadores têm apontado nos últimos anos, alguns deles por ora aqui citados. Segundo, a

2 Tradução da autora. 
BNCC é um documento profícuo para pensar como outros campos discursivos também têm tomado o espaço educacional e pedagógico para assumir posições dessa ordem. Para além do campo econômico, como destacado a partir dos estudos de Laval (2004), o campo estético também pode servir como uma lente potente para pensar como as questões de ordem social e individual têm influenciado as formulações educacionais. Lipovestsky (2016), ao sinalizar o imperativo da renovação constante, também assinala como esses aspectos têm colaborado para uma destradicionalização da vida e dos espaços sociais. Desse modo, as reflexões trazidas por tais autores auxiliam na complexificação da leitura desses fenômenos para além do campo econômico, apontando para tendências mais individualistas, de um culto a si quase que perpétuo.

A análise dos documentos aqui proposta também tornou possível que alguns destaques fossem possíveis a partir das concepções de aprendizagem. As DCN, marcadas pela educação com qualidade pedagógica e social, já anunciavam, em suas proposições, tendências que relacionavam a aprendizagem como um processo de aprendizagem permanente. Entretanto, o que a Base talvez se diferencie de tais proposições seja justamente nas questões emocionais, intuitivas, criativas, que pressupõem uma radicalização dos processos de individualização, como apontam as análises de Ciervo e Silva (2019). Também se reitera que esse texto trata de um recorte de pesquisas ainda em andamento. Pela proposta de análise, focou-se exclusivamente na análise de documentos a partir de um exercício metodológico específico. Dito isso, destaca-se que não houve inserção em campo em espaços escolares para outras análises que evidenciassem como tais reformulações curriculares em voga têm impactado as escolas brasileiras.

Assim, mostra-se potente aprofundar pesquisas nas quais seja possível averiguar e problematizar como o excesso de individualização, evidente nas recentes propostas de reformulação curricular, especialmente pela ênfase na linguagem da aprendizagem, pode impactar em cenários amplamente desiguais, como é o caso brasileiro. Do mesmo modo, cabe ressaltar que no atual momento educacional brasileiro, há tendências quase antagônicas à própria BNCC e ao tipo de proposição por ela sugerida. Tal fenômeno pode ser exemplificado pelo projeto das escolas cívico-militares a partir do Decreto n. 10.004/19. Apesar de impactar de outras formas a Educação Básica, evidencia que as tendências propostas na BNCC não estão garantidas no tempo presente e concorrem com perspectivas educacionais mais voltadas à disciplina e aos aspectos ditos tradicionais do espaço escolar, entre outros exemplos possíveis.

Apesar dessas considerações, as evidências dos documentos analisados permitem diagnosticar o quão problemáticas podem se tornar essas reformulações, uma vez que os sujeitos são convidados a serem seus próprios designers, em condições de partidas não marcadas pela igualdade, mas pelo seu radical oposto: a desigualdade. Assim, talvez a escola da aprendizagem para as competências seja uma escola que em suas próprias proposições já se define como um lugar de sucesso para poucos. Por sua vez, a possibilidade de a escola dar condições de maior autonomia na construção dos percursos de aprendizagem dos sujeitos, em oposição a um tipo de escola anterior, marcada pela homogeneização e classificação, também são aspectos que podem ser compreendidos como positivos, apesar das possíveis implicações problematizadas neste artigo. 


\section{REFERÊNCIAS}

BIESTA, Gert. O dever de resistir: sobre escolas, professores e sociedade. In: Educação, v. 41, n. 1, jan./abr., p. 21-29, 2018.

. The beautiful risk of education. London: Paradigm Publishers, 2013a.

. Para além da aprendizagem: educação democrática para um futuro humano. Belo Horizonte: Autêntica, 2013b.

BRASIL. Ministério da Educação. Planejando a próxima década: conhecendo as 20 metas do Plano Nacional de Educação. Brasília, 2014. Disponível em: http://pne.mec.gov.br/ images/pdf/pne_conhecendo_20_metas.pdf. Acesso em: 12 fev. 2018.

BRASIL. Ministério da Educação. Base Nacional Comum Curricular: educação é a base. Brasília, 2018. Disponível em: http://basenacionalcomum.mec.gov.br/. Acesso em: 8 abr. 2018.

BRASIL. Ministério da Educação. Diretrizes Curriculares Nacionais Gerais para a Educação Básica. Brasília, 2013. Disponível em: http://portal.mec.gov.br/. Acesso em: 13 dez. 2017.

CIERVO, Tássia J. R.; SILVA, Roberto R. D. da. A centralidade das competências socioemocionais nas políticas curriculares contemporâneas no Brasil. In: E-Curriculum, v. 17, n. 2, p. 382-401, abr./jun. 2019.

FOUCAULT, Michel. A ordem do Discurso. Tradução Laura Fraga de Almeida Sampaio, 16. ed. São Paulo: Edições Loyola, 2008.

GOODSON, Ivor. F. As políticas de currículo e de escolarização. Petrópolis, RJ: Vozes, 2008 .

LAVAL, Christian. A escola não é uma empresa: o neo-liberalismo em ataque ao ensino público. Londrina: Editora Planta, 2004.

LIPOVETSKY, Gilles. Da leveza: rumo a uma civilização sem peso. Barueri, SP: Manole, 2016.

LIPOVESTKY, Gilles; SERROY, Jean. A estetização do mundo: viver na era do capitalismo artista. São Paulo: Companhia das Letas, 2015.

LOPES, Maura. Corcini. ¿Qué hay entre las políticas de inclusión y las prácticas pedagógicas en la escuela? In: Revista Sudamérica, v. 9, p. 73-94, 2018. Disponível em: https:// 
fh.mdp.edu.ar/revistas/index.php/sudamerica/article/view/2986/3060. Acesso em: 20 jun. 2019.

MASSCHELEIN, Jan; SIMONS, Maarten. A língua da escolar: alienante ou emancipadora? In: LARROSA, Jorge (Org.). Elogio da escola. Belo Horizonte: Autêntica, 2017.

NARODOWSKI, Mariano. Un mundo sin adultos: família, escuela y médios a la desaparición de la autoridade de los mayores. Buenos Aires: Debate, 2016.

NOGUERA-RAMIREZ, Carlos. E. Pedagogia e governamentalidade ou da Modernidade como uma sociedade educativa. Belo Horizonte: Autêntica, 2011.

RIOS, Terezinha Azerêdo. A construção permanente da competência. In: ROVAI, Esméria (Org.). Competência e Competências: contribuição crítica ao debate. São Paulo: Cortez, 2010.

ROVAI, Esméria. Introdução. In: ROVAI, Esméria (Org.). Competência e Competências: contribuição crítica ao debate. São Paulo: Cortez, 2010.

SILVA, Roberto Rafael, D. da. "A Base Curricular que reverencia a financeirização". SANTOS, João Vitor. Revista IHU On-Line, 4 dez. 2017. Disponível em: http://www.ihuonline.unisinos.br/artigo/7145-base-nacional-comum-curricular-bncc. Acesso em: 4 abr. 2019.

SILVA, Roberto Rafael, D. da. Estetização Pedagógica, Aprendizagens Ativas e Práticas Curriculares no Brasil. In: Educação \& Realidade, v. 43, n. 2, abr./jun., p. 551-568, 2018. Disponível em: http://dx.doi.org/10.1590/2175-623667743. Acesso em: 20 jun. 2019.

SIMONS, Maarten; MASSCHELEIN, Jan. Experiências escolares: uma tentativa de encontrar uma voz pedagógica. In: LARROSA, Jorge (Org.). Elogio à escola. Belo Horizonte: Autêntica, 2017.

VEIGA-NETO, Alfredo. Foucault \& Educação. Belo Horizonte: Autêntica, 2011.

\section{DAdOS DA AUTORA:}

\section{DeISe ANDreia EnZweILer}

Doutoranda do Programa de Pós-Graduação em Educação da Universidade do Vale do Rio dos Sinos. Rio Grande do Sul/RS-Brasil. Integrante do Grupo de Estudos e Pesquisa em Inclusão da Universidade do Vale do Rio dos Sinos. Rio Grande do Sul/RS-Brasil. deiseandreia@gmail.com.

Submetido em: 31-1-2020

Aceito em: 17-11-2020 